\title{
ANALYSIS OF MECHANICAL STRENGTH OF CONNECTION BETWEEN COMPOSITE AND ALUMINUM SHEET METAL USING HOLE CLINCHING PROCESS
}

\author{
Ravenskya Hana Hardiyantie ${ }^{1}$, Lazuardy Rahendra $\mathbf{P}^{\mathbf{2}}$, \\ Teknik Dirgantara - Institut Teknologi Dirgantara Adisutjipto Yogyakarta \\ hanaravenskya@gmail.com, lazuardyrp@itda.ac.id
}

\begin{abstract}
Aluminum and composite materials are the types of materials that are used to construct structures on aircraft airframes. It is not uncommon for both types of materials to be used together with the joining method. In the process of connecting between two types of material in the aircraft structure, it is mostly carried out by the riveting method. This process is carried out by making a hole in the two materials according to the rivet diameter and then the hole diameter is then filled with rivets and the riveting process is carried out. The process uses rivets so that it will relatively increase the weight of the structure because there is additional rivet material. In this study, the objectives are to determine the mechanical strength of the joint between the composite and aluminum sheet metal using the mechanical clinching and riveting processes. The method used is an experimental method, namely by making test specimens with composite and aluminum, solid rivet type fasteners and punches to determine the connection of the riveting, the drilling process is carried out with a hole diameter of $3.5 \mathrm{~mm}$, for the clinching method with variations in the diameter of the punch $3.5 \mathrm{~mm}, 4.0 \mathrm{~mm}$., and $4.5 \mathrm{~mm}$. Then the tensile test, macro photo test were carried out. The results obtained from this research are that the maximum load increase in the specimen tested by clinching is because the damage length (gap) value is obtained at the joint boundary between the rivet and the test material.
\end{abstract}

Keywords: Mechanical Clinching, Riveting, Composite, Aluminum

\section{Pendahuluan}

Material aluminium dan material komposit merupakan jenis material yang digunakan sebagai penyusun struktur pada airframe pesawat terbang tidak jarang kedua jenis material tersebut digunakan bersamaan dengan metode penyambungan (joining). Tidak jarang proses penyambungan antara jenis material aluminium dan jenis material menimbulkan permasalahan pada struktur pesawat terbang, dimana sambungan yang terdapat pada struktur komposit menjadi titik lemah pada bagian struktur. Pada proses penyambungan antara dua jenis material pada struktur pesawat terbang kebanyakan dilakukan dengan metode riveting ${ }^{[1][2][3]}$ Proses ini dilakukan dengan melubangi kedua material sesuai dengan diameter rivet dan selanjutnya pada diameter hole tersebut lalu diisi universal rivet dan selanjutnya dilakukan proses riveting.

Proses tersebut menggunakan rivet sehingga relatif akan menambah berat struktur karena ada tambahan material rivet. Berdasarkan latar belakang tersebut maka perlu diupayakan metode penyambungan untuk mengurangi permasalahan yang timbul akibat proses penyambungan dengan metode riveting. Proses tersebut adalah clinching. Clinching merupakan metode penggabungan material yang berbeda jenisnya.

Jacek Mucha, Waldemar Witkowski dari Faculty of Mechanical Engineering and Aeronautics, Rzeszow University of Technology Polandia, Menganalisis kekuatan structure rivet. untuk keempat sistem penggabungan spesimen jenis Single Lap Joint dibuat dan diuji dengan uji geser, jenis rivet yang digunakan ada empat yaitu Aluminium-steel blind rivet (BR), Aluminium-steel blind hermetic rivet (BHR), Aluminium alloy rivet for closing up (COUR) and solid self-piercing steel rivet (SSPR), sambungan kombinasi baja DC01 dan lembaran paduan 
aluminium EN AW-5754 dengan ketebalan 2mm. Standar yang digunakan ISO / DIS 12996. .[4][5][6] Kapasitas beban maksimum sambungan ditentukan oleh kekuatan sambungan. Untuk sambungan dengan rivet aluminium baja. Kekuatan sambungan SSPR memiliki kekuatan 5.26 $\mathrm{kN}$ paling baik dibandingkan dengan yang lain. Anna Galinska, Cezary Galinski dari Institute of Aeronautics and Applied Mechanics Faculty of Power and Aeronautical Engineering, Warsaw University of Technology Polandia, penggabungan dua jenis spesimen antara composite carbon fiber dengan aluminium sheet metal ini bisa digabungkan dengan beberapa metode yaitu Self-Piercing Riveting, Friction Riveting, Cilincing, Non-adhesive form-locked joints, and Loop joints.

Penggabungan dua spesimen aluminium AA6061 dengan carbon fiber dengan diameter $8.2 \mathrm{~mm}$, eagle $0.5 \mathrm{~mm}$, dengan diameter punch bervariasi yaitu $6.6 \mathrm{~mm}, 6.8 \mathrm{~mm}, 7.0 \mathrm{~mm}$. kapasitas beban yang didapatkan tergantung dari berapa besar diameter pengeboran, dalam hal ini untuk diameter punch $7.0 \mathrm{~mm}$ memiliki beban maksimum $2.25 \mathrm{kN}$ dengan intensitas kegagalan yang sangat kecil dan paling baik dibandingkan dengan yang lain. Dimas Surya Andhika, Teknik Penerbangan 2018, dengan judul "Pengaruh pengaruh diameter hole terhadap kekuatan single lap joint pada material Aluminium 2024-T3 dalam kegiatan aircraft maintenance”.

Penelitian ini difokuskan untuk menganalisis pengaruh diameter hole terhadap sambungan single lap joint dengan proses riveting yang divariasikan diameter hole nya. Perlakuan sambungan pada material adalah riveted single lap joint. Proses riveting dilakukan oleh personil yang memiliki sertifikat keahlian dalam bidang riveting. Selanjutnya hasil riveting dilakukan pengujian tarik dan foto makro. Hasil pengujian menunjukkan bahwa maksimum oversize saat proses drilling pada diameter $3.4 \mathrm{~mm}$. Untuk membentuk sebuah struktur pesawat, lembaran-lembaran skin pesawat harus dikencangkan antara yang satu dengan yang lain. Pengencangan tersebut biasanya dilakukan dengan menggunakan solid rivet yang terbuat dari paduan aluminium. Rivet adalah sebuah perangkat untuk mengencangkan dua buah lembaran logam maupun non logam. Rivet berbentuk silinder kecil dengan kepala yang dibentuk sesuai dengan kebutuhannya. Kepala bagian atas rivet disebut dengan factory head sedangkan bagian bawahnya disebut dengan bucktail. ${ }^{[7][8]}$

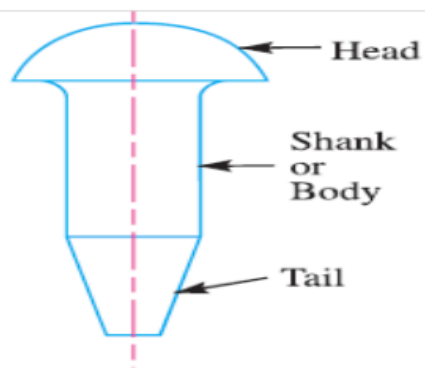

Gambar 1 Bagian-bagian rivet

Pada pengaplikasiannya, rivet dimasukkan ke dalam lubang yang telah dibuat dengan menggunakan bor dengan ukuran diameter yang sedikit lebih besar dari diameter rivet tersebut, kemudian kepala rivet dipukul berulang-ulang dengan menggunakan rivet gun yang biasanya bertenaga pneumatic, sedangkan bagian bawahnya ditahan dengan menggunakan bucking bar. Sambungan dengan menggunakan rivet dipasang secara permanen, maka untuk melepasnya kembali perlu dilakukan pengeboran. Ada dua tipe rivet yang umum digunakan, yaitu: The Solid Shank Rivet dan The Special Blind Rivet. The Solid Shank Rivet adalah pembentukan shop head yang dilakukan dengan menggunakan bucking bar yang posisi pengerjaannya dilakukan dalam dua sisi. Sedangkan The Special Blind Rivet merupakan pembentukan shop head yang dilakukan tanpa menggunakan bucking bar. Pada beberapa riveted structure yang tentu susah sekali untuk mendapatkan posisi pengerjaan pada dua sisi atau dimana ruangan yang ada sangat 
terbatas dan tidak memungkinkan untuk menggunakan bucking bar. Untuk penggabungan pada parts tersebut dibuatlah rivet spesial yang pemasangannya hanya dilakukan satu sisi. ${ }^{[9]}$

\section{Metode Penelitian}

Metode ini dilakukan dengan menggunakan eksperimental, yaitu dengan membuat spesimen uji dengan komposit dan aluminium, fastener jenis rivet solid serta punch untuk mengetahui sambungan dari riveting maka dilakukan proses drilling dengan diameter hole 3.5 $\mathrm{mm}$, untuk metode clinching dengan variasi diameter punch $3.5 \mathrm{~mm}, 4.0 \mathrm{~mm}$, dan $4.5 \mathrm{~mm}$. Kemudian dilakukan pengujian tarik, pengujian foto makro. Dalam penelitian ini penulis menggunakan beberapa metode yang digunakan, yaitu:

a. Metode Wawancara, yaitu metode mengumpulkan data dan informasi terkait dengan penelitian yang akan dilakukan dengan cara bertanya langsung kepada narasumber yang berkompeten dalam bidang komposit dan aluminium maupun proses riveting dan clinching pada material komposit dan aluminium baik itu dosen, laboran tempat melakukan penelitian dan lain sebagiannya.

b. Metode Studi Pustakan, yaitu metode pengumpulan data dengan membaca buku, artikel atau jurnal penelitian yang telah dilakukan sebelumnya.

c. Persiapan alat, bahan dan spesimen uji yaitu mempersiapkan segala sesuatu untuk mendukung proses penelitian. Pada penelitian ini penulis menggunakan material Aluminium 2024-T3, Composite carbon fibre, rivet, punch.

d. Proses riveting adalah proses penggabungan antara 2 pelat. Dalam penelitian ini penulis menggunakan spesimen single lap joint, serta proses riveting dilakukan di SKATEK 043 Adisutjipto dan dikerjakan oleh mekanik berlisensi.

e. Hasil rivet sesuai standar yaitu bahwa hasil dari proses riveting memenuhi standar yang sudah ditetapkan, antara lain:

- Edge Distance (jarak titik pusat lubang rivet sampai pada sisi pelat) adalah 2.5D sampai 4D. Pada penelitian ini penulis menerapkan 4D untuk edge distance. Untuk rivet yang digunakan berdiameter $3.5 \mathrm{~mm}$, maka edge distance adalah 4 X3.5 = 14 mm.

- Shop head (kepala rivet baru yang terbentuk setelah proses riveting) adalah 1.5D, maka shop head adalah $1.5 \times 3.2 \mathrm{~mm}=5.25 \mathrm{~mm}$.

f. Pengujian yang dilakukan adalah uji tarik dan uji foto makro, tujuan dari dilakukannya pengujian tarik adalah untuk mengetahui hasil sambungan riveting dan variasi dengan menggunakan metode clinching. Pada penelitian ini menggunakan perlakuan single lap joint. Serta tujuan dilakukannya pengujian foto makro adalah untuk mengetahui hasil sambungan antara riveting dengan clinching dengan diameter punch $3.5 \mathrm{~mm}, 4.0 \mathrm{~mm}$, $4.5 \mathrm{~mm}$.

Analisis dan pembahasan berisi data real hasil pengujian baik pada spesimen composite, spesimen riveting, spesimen clinching dan spesimen foto makro. Data hasil pengujian dianalisis dari hasil pengujian yang kemudian dijadikan sebagai pembahasan dan kesimpulan.

\section{Hasil dan Analisis}

Pada penelitian ini dilakukan pengujian tarik pada composite carbon fiber, dalam pengujian tarik ini menggunakan 3 spesimen uji agar hasil yang didapat lebih valid. Dimana untuk untuk pembuatan dan pengujian tarik composite carbon fiber menggunakan ASTM D3039M. Dari hasil pengujian 3 spesimen composite carbon didapatkan hasil rata-rata pada maksimum load yaitu sebesar 8785 Newton, rata-rata pada yield strength yaitu sebesar 94 $\mathrm{N} / \mathrm{mm}^{2}$ dan rata-rata tensile strength yaitu sebesar $142 \mathrm{~N} / \mathrm{mm}^{2}$. Untuk lebih jelas tentang hasil pengujian tarik composite fiber. 


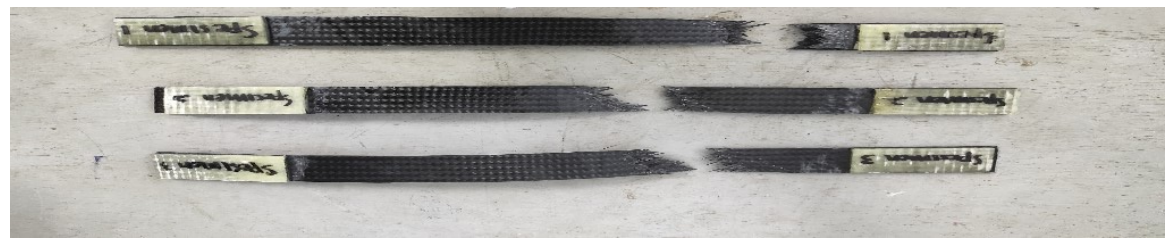

Gambar 2. Hasil uji tarik Composit Carbon

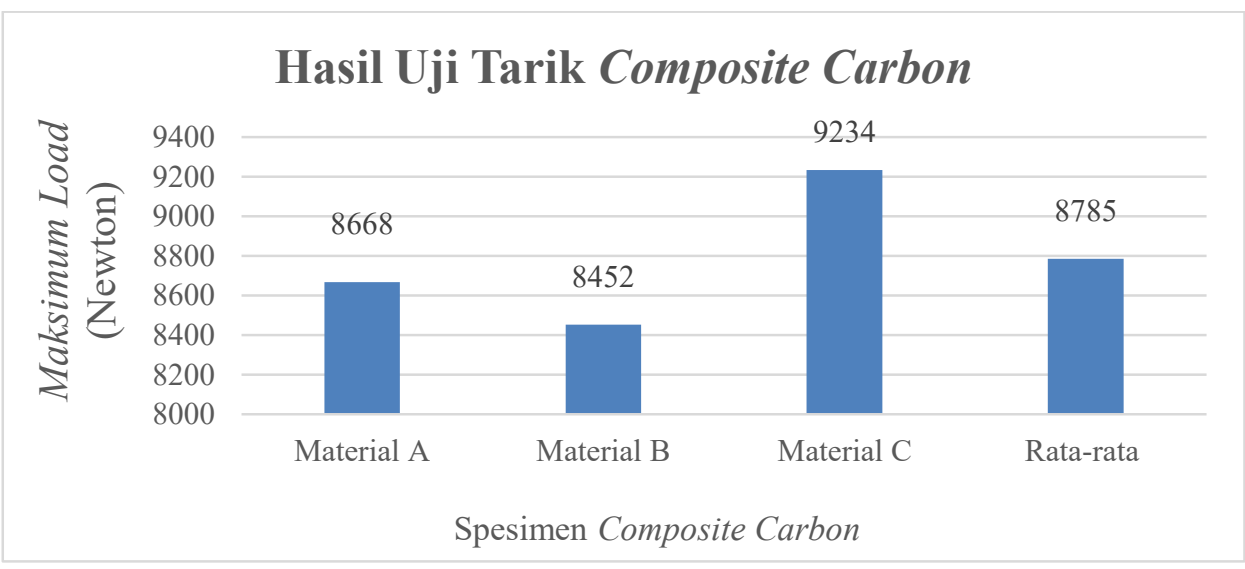

Gambar 2. Grafik maksimum load spesimen composit carbon

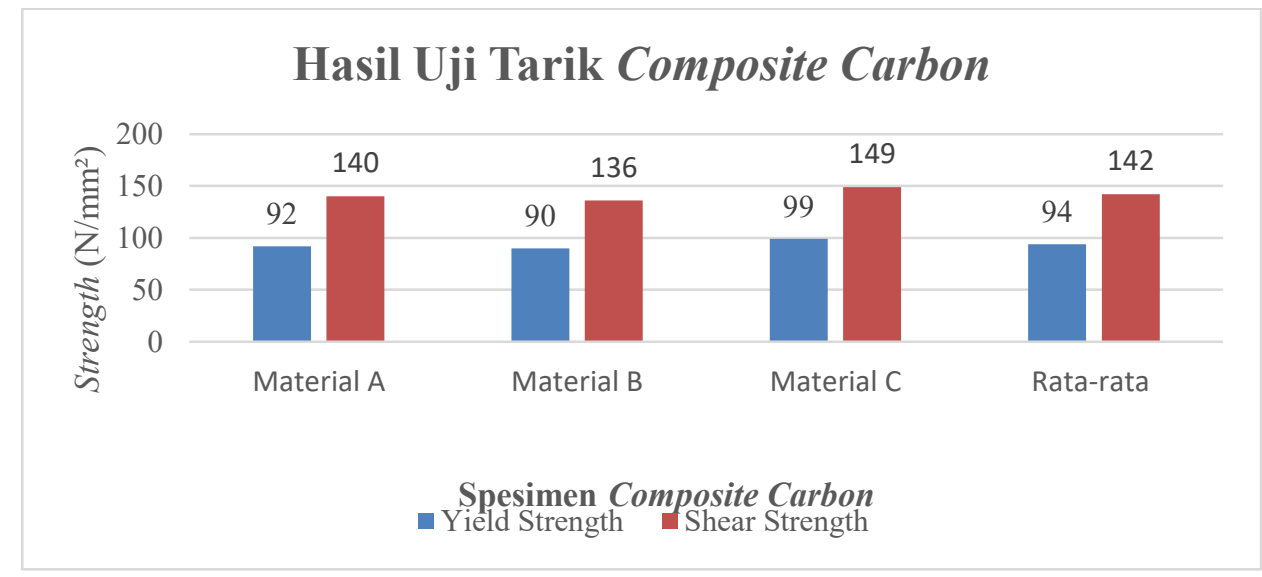

Gambar 3. Grafik yield strength dan shear strength spesimen composite carbon

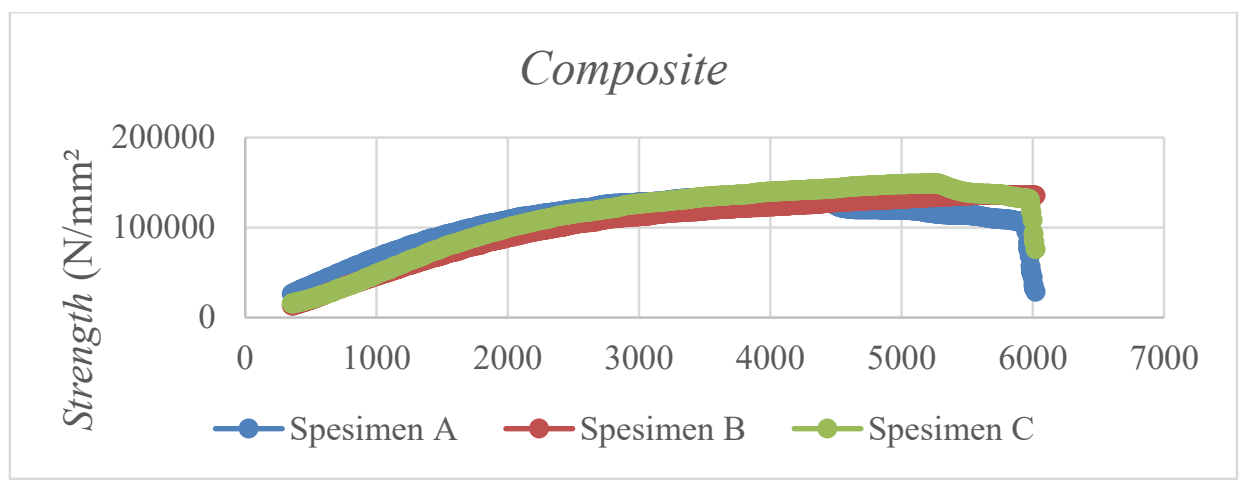

Gambar 4. Curve yield strength dan shear strength spesimen composite carbon 
Dari hasil penelitian yang telah dilakukan setiap benda uji memiliki nilai maksimum load yang berbeda, didapatkan hasil kekuatan yang paling tinggi ada pada spesimen C composit carbon fiber yaitu sebesar 9234 Newton dan paling rendah pada spesimen B composit carbon fiber dengan nilai 8452 Newton. Hal ini disebabkan karena pembuatan spesimen composit carbon fiber dikerjakan manual dengan tangan manusia. Dalam pengujian tarik single lap joint menggunakan sheet metal Aluminium 2024-T3, Composite fiber, dan rivet solid dengan diameter $3.5 \mathrm{~mm}$. Standar yang digunakan dalam pengujian menggunakan standar ISO/DIS 12996 (dimensi dan layout pada gambar 3.23). Dalam pengujian ini penulis membutuhkan 3 spesimen riveting. Dari hasil pengujian spesimen dengan riveting didapatkan hasil rata-rata pada maksimum load yaitu sebesar 1059 Newton, rata-rata pada yield strength yaitu sebesar $113 \mathrm{~N} / \mathrm{mm}^{2}$ dan rata-rata tensile strength yaitu sebesar $151 \mathrm{~N} / \mathrm{mm}^{2}$.

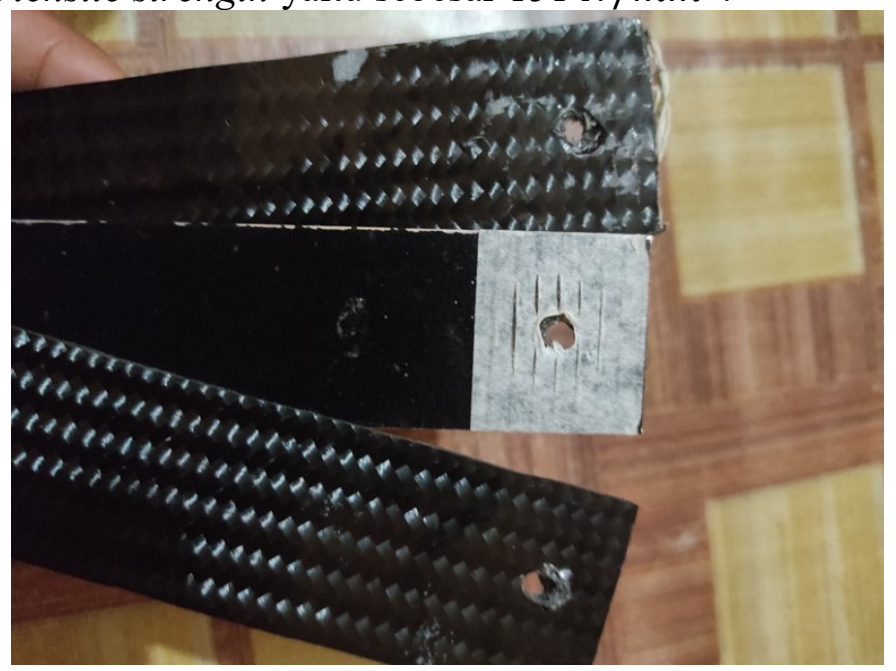

Gambar 5 Hasil uji tarik spesimen riveting

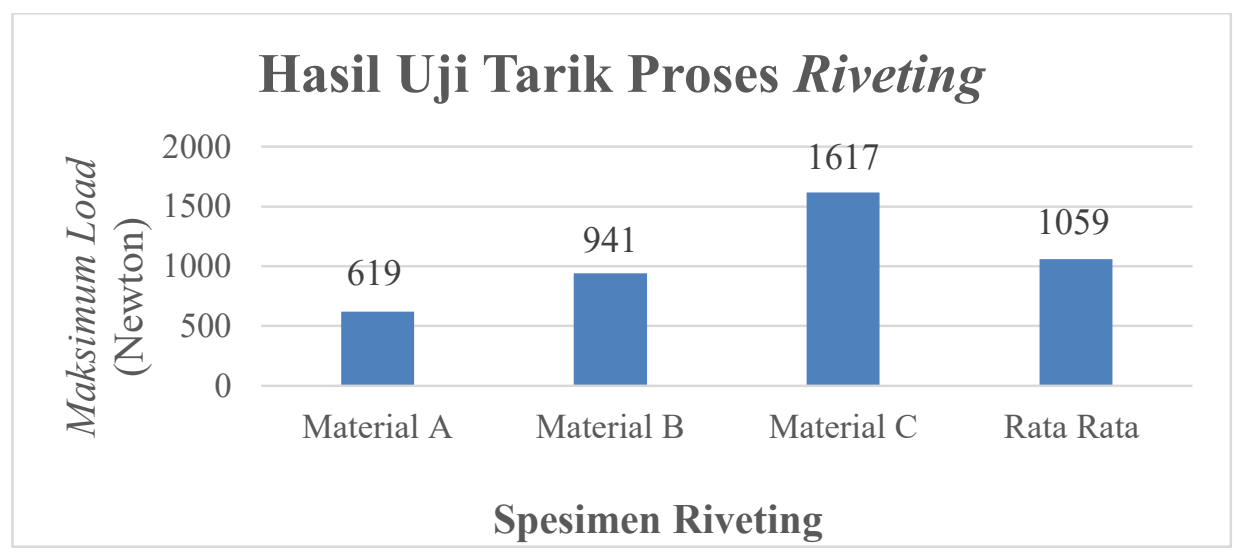

Gambar 6. Grafik maksimum load spesimen riveting 


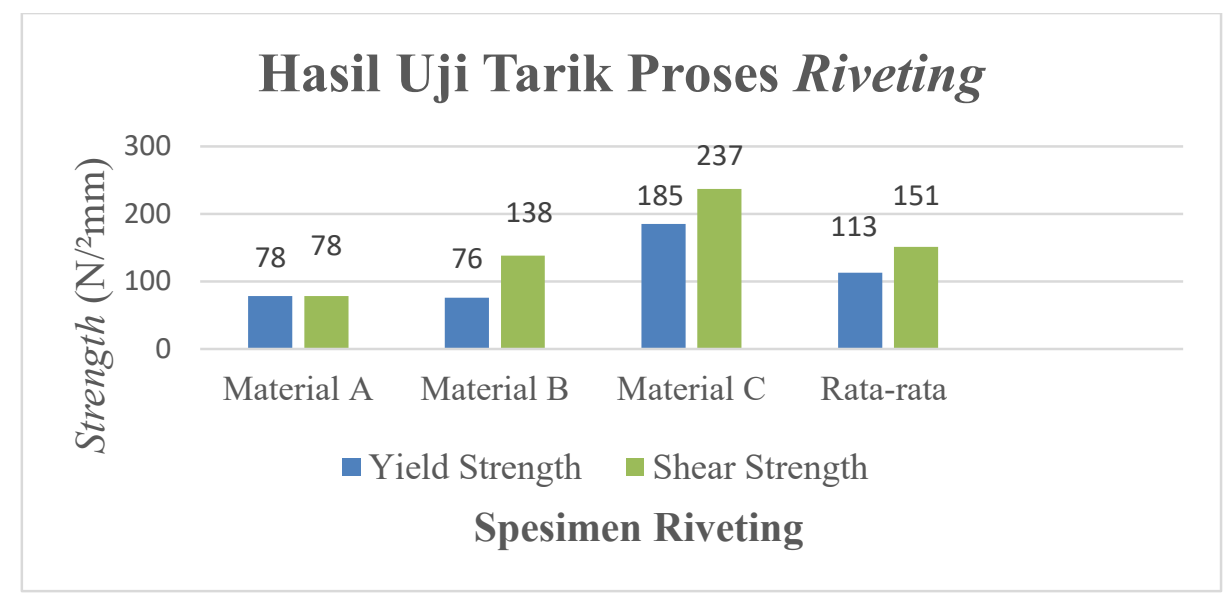

Gambar 7. Grafik yield strength dan shear strength spesimen riveting

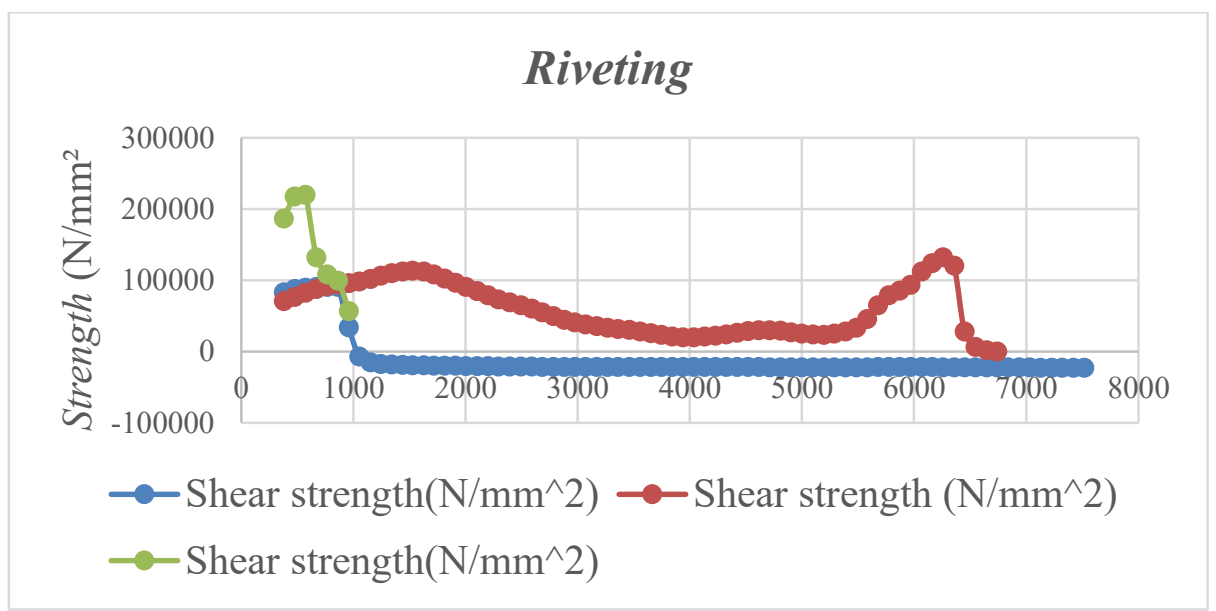

Gambar 8. Curve yield strength dan shear strength spesimen riveting

Dari hasil penelitian yang telah dilakukan setiap benda uji memiliki nilai maksimum load yang berbeda, didapatkan hasil peningkatan kekuatan yang signifikan paling tinggi ada pada spesimen C riveting yaitu sebesar 1617 Newton dan paling rendah pada spesimen A riveting dengan nilai 619 Newton. Hal ini disebabkan karena seberapa kuat dari rivet tersebut untuk menahan beban yang diberikan.

Dalam pengujian dengan metode clinching menggunakan sheet metal Aluminium 2024T3, Composite fiber, dengan diameter $3.5 \mathrm{~mm}, 4.0 \mathrm{~mm}, 4.5 \mathrm{~mm}$ dan punch (alat khusus yang dibuat untuk dilakukan pengepresan). Dalam pengujian ini membutuhkan 3 spesimen. Dari hasil pengujian spesimen clinching didapatkan hasil rata-rata pada maksimum load yaitu sebesar 1884 Newton, rata-rata pada yield strength yaitu sebesar $233 \mathrm{~N} / \mathrm{mm}^{2}$ dan rata-rata tensile strength yaitu sebesar $344 \mathrm{~N} / \mathrm{mm}^{2}$. 


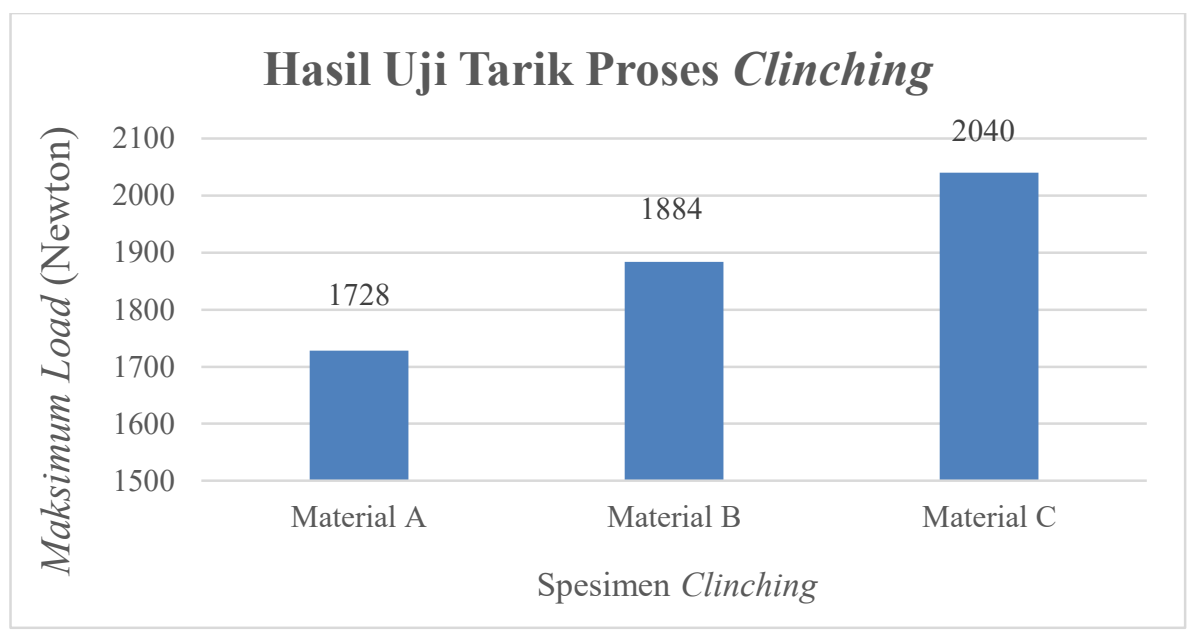

Gambar 9. Grafik maksimum load spesimen clinching

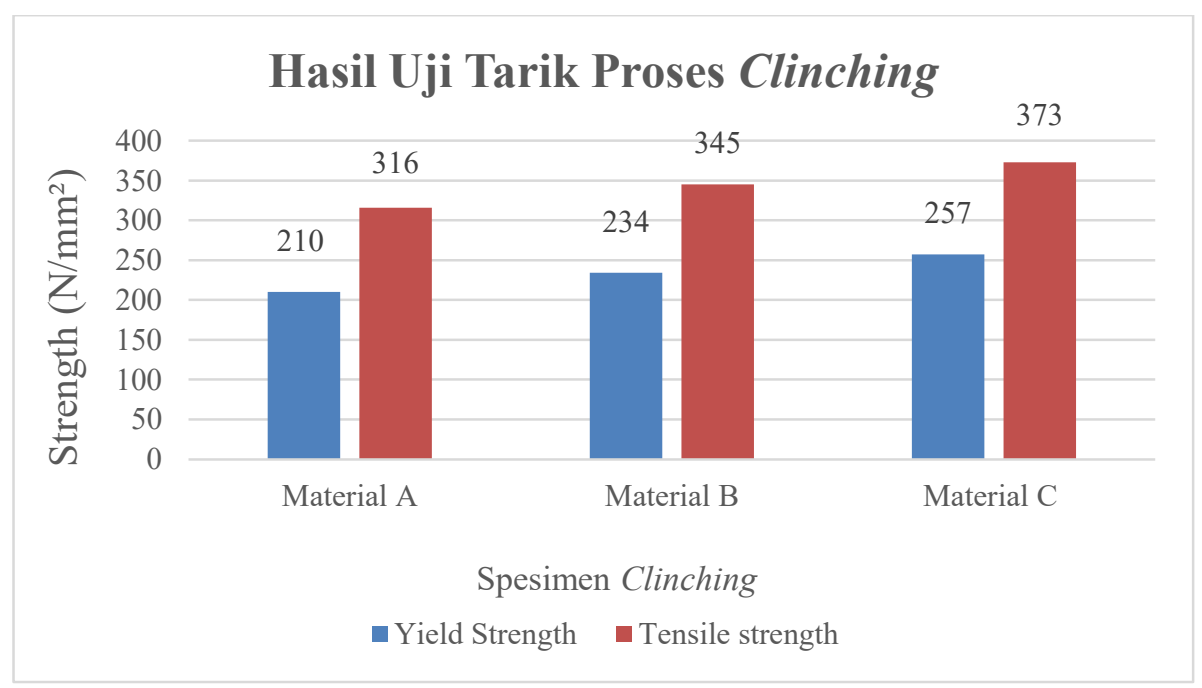

Gambar 10. Grafik yield strength dan tensile strength spesimen clinching

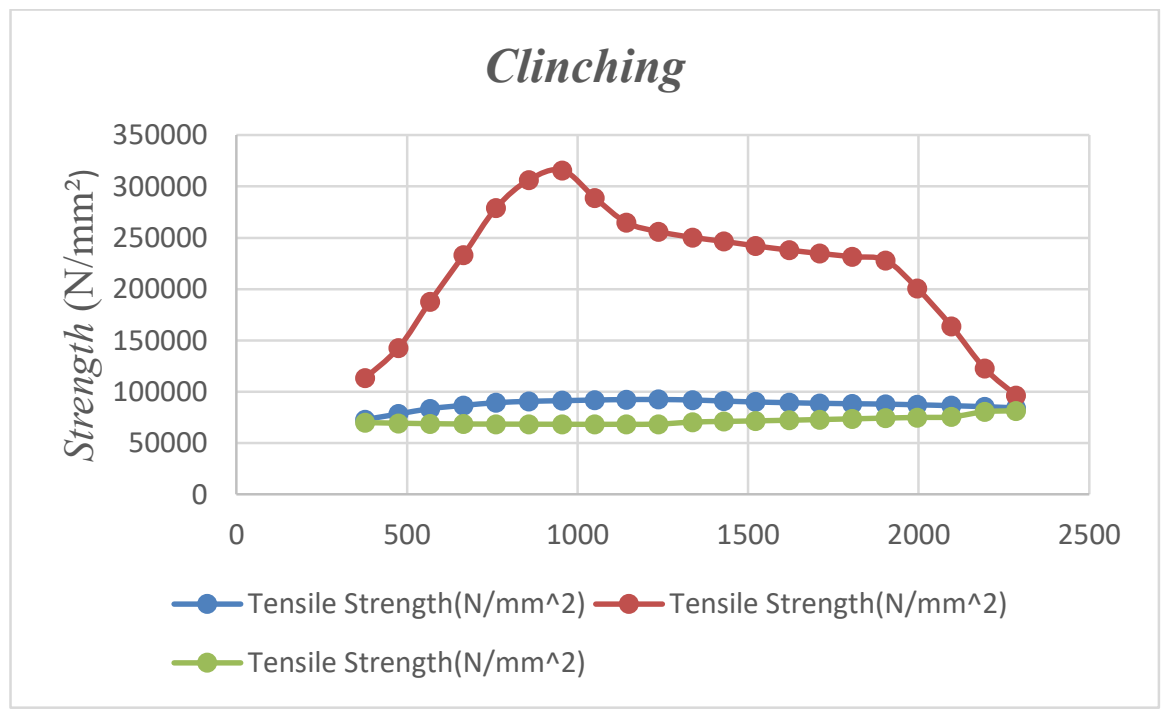

Gambar 11 Curve yield strength dan Tensile strength spesimen clinching 
Dari hasil penelitian yang telah dilakukan setiap benda uji memiliki nilai maksimum load yang berbeda, didapatkan hasil kekuatan yang cukup signifikan paling tinggi ada pada spesimen C clinching yaitu sebesar 2040 Newton dan paling rendah pada spesimen A clinching dengan nilai 1728 Newton. Hal ini disebabkan karena variasi diameter hole pada material uji. Dari penelitian yang dilakukan pada spesimen dengan riveting didapatkan hasil rata-rata pada maksimum load yaitu sebesar 1059 Newton, rata-rata pada yield strength yaitu sebesar 113 $\mathrm{N} / \mathrm{mm}^{2}$ dan rata-rata tensile strength yaitu sebesar $151 \mathrm{~N} / \mathrm{mm}^{2}$. Dari penelitian yang dilakukan pada spesimen dengan clinching didapatkan hasil rata-rata pada maksimum load yaitu sebesar 1884 Newton, rata-rata pada yield strength yaitu sebesar $233 \mathrm{~N} / \mathrm{mm}^{2}$ dan ratarata tensile strength yaitu sebesar $344 \mathrm{~N} / \mathrm{mm}^{2}$.

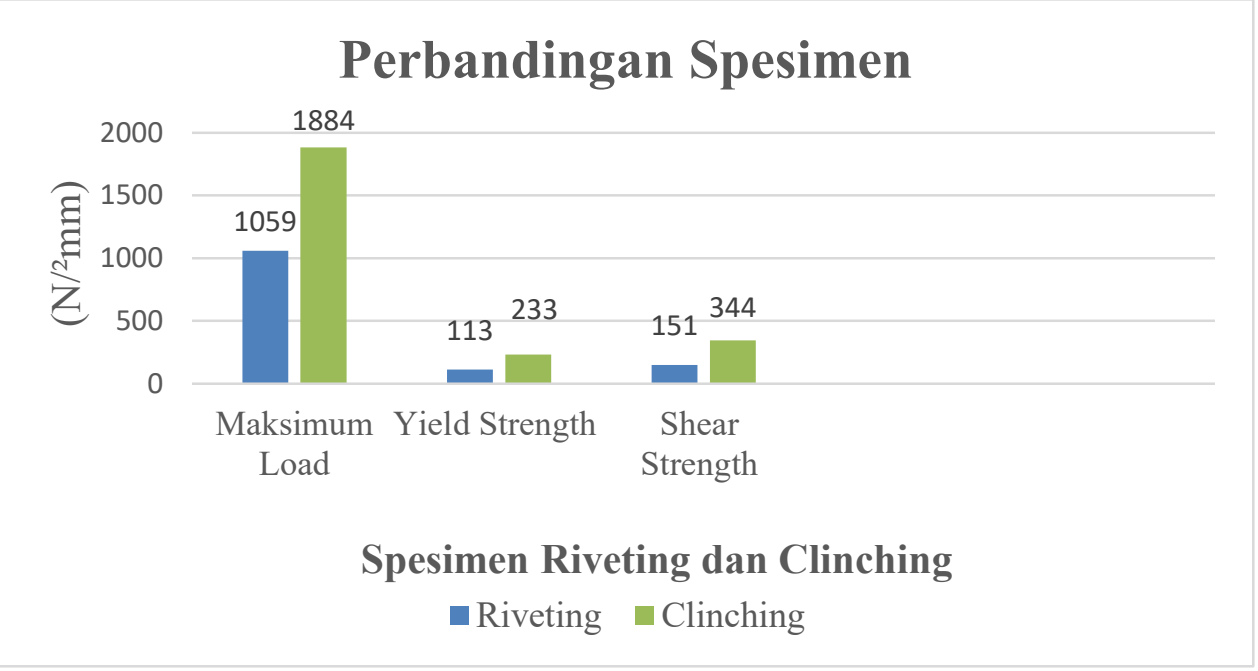

Gambar 12. Grafik maksimum load, yield strength dan shear strength spesimen riveting clinching

Dari hasil penelitian ini didapatkan peningkatan maksimum load pada spesimen yang diuji dengan menggunakan metode clinching karena pada spesimen tersebut didapatkan nilai damage length (Celah) pada batas sambungan antara rivet dengan material uji. Hal ini menyebabkan terjadinya peningkatan nilai maksimum load yang diterima oleh masing-masing spesimen clinching. Damage length tersebut akan menahan rivet agar tidak langsung patah Ketika menerima beban geser. Hal ini juga dapat dibuktikan dengan pengamatan yang dilakukan menggunakan alat mikroskop metalografi dan menggunakan perbesaran hingga 40 kali ukuran aslinya. Setelah penampang lap joint bisa dilihat dengan jelas, kemudian mengukur damage length (celah) dengan menggunakan software image raster. Dalam pengujian ini bertujuan untuk melihat kekuatan mekanis hasil sambungan antara riveting dengan clinching pada spesimen single lap joint. Gambar hasil pengamatan berupa tingkat kekuatan mekanis pada sambungan antara riveting dengan clinching, dengan parameter panjangnya celah (damage length). Pengujian foto makro ini dilakukan sebelum dilakukannya pengujian tarik pada spesimen riveting, dikarenakan dalam pengujian tarik single lap joint memerlukan luas penampang berupa ukuran diameter rivet yang didapatkan dari pengujian foto makro.Pengamatan mikroskop pada spesimen riveting dengan diameter $3.5 \mathrm{~mm}$ didapatkan damage length antara sambungan rivet hasilnya adalah hampir tidak adanya damage length yang terdapat pada sambungan rivet, jika dilihat dengan kasat mata pada hasil foto mikroskop. Perhitungan menggunakan software image raster juga tidak mendefinisikan angka karena damage length yang mungkin terlalu kecil atau bisa disebut tidak ada. 


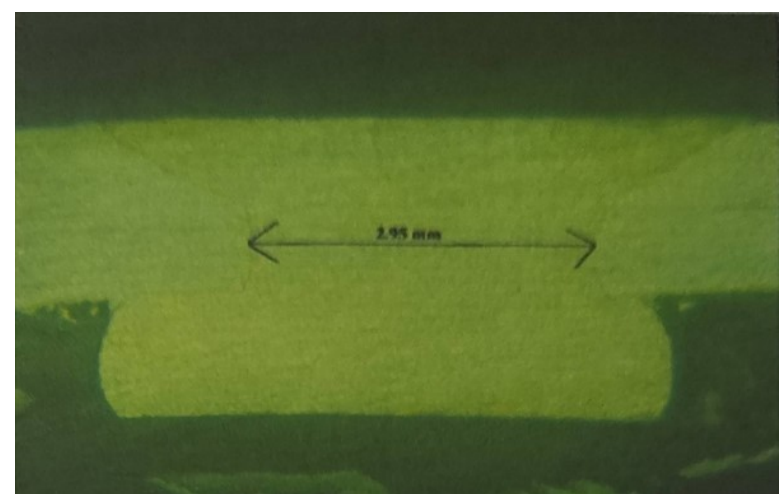

Gambar 13. Hasil foto makro spesimen dengan riveting

Pengamatan miksorskop pada spesimen metode clinching dengan diameter $3.5 \mathrm{~mm}, 4.0$ $\mathrm{mm}$, dan $4.5 \mathrm{~mm}$. Hasilnya adalah terdapat damage length antara sambungan rivet, setelah dilakukan pengukuran menggunakan software image raster damage length tersebut terjadi karena pada metode ini dilakukan pengepresan terlebih dahulu yang menyebabkan diameter hole nya lebih besar dari diameter punch.

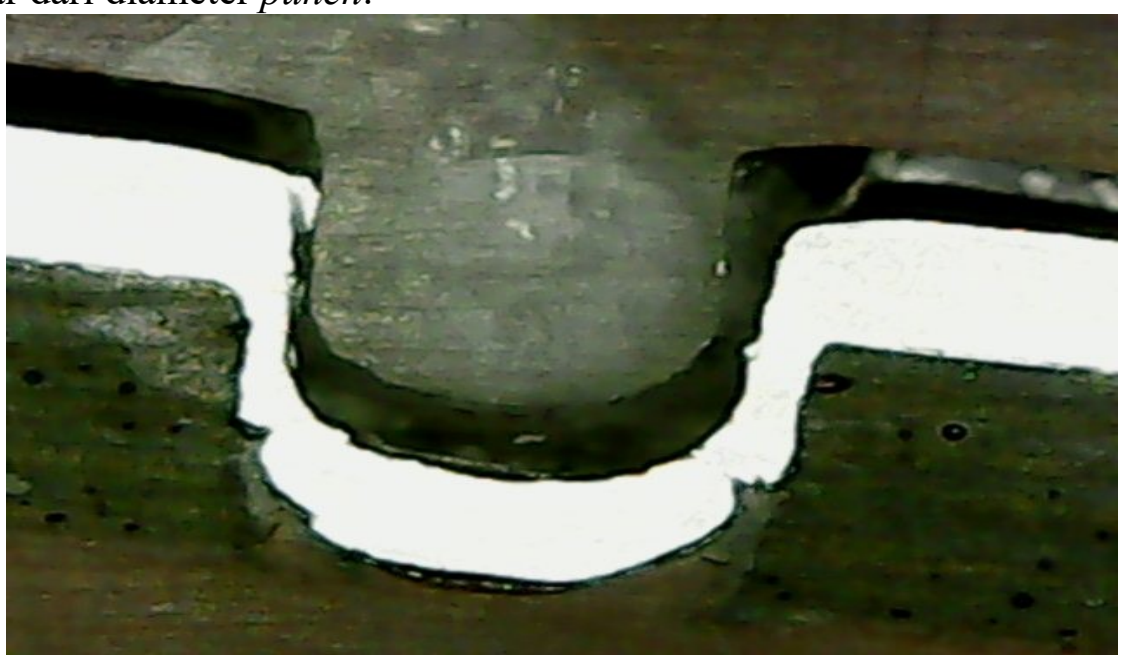

Gambar 14 Hasil foto makro spesimen metode clinching dengan diameter $3.5 \mathrm{~mm}$

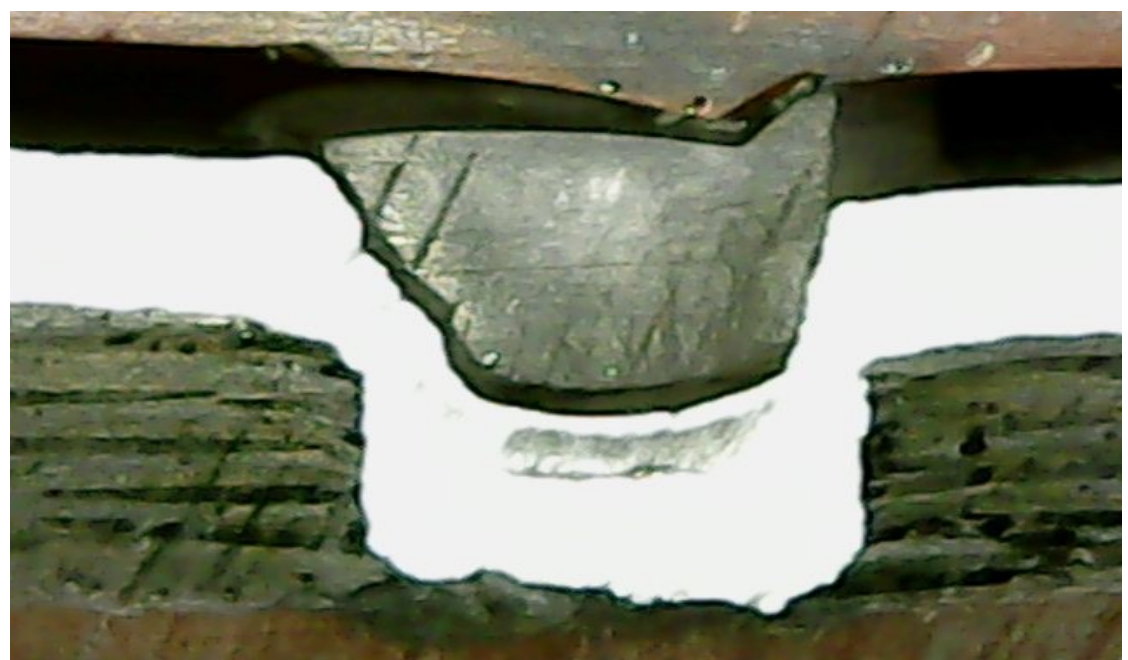

Gambar 15. Hasil foto makro spesimen metode clinching dengan diameter $4.0 \mathrm{~mm}$ 


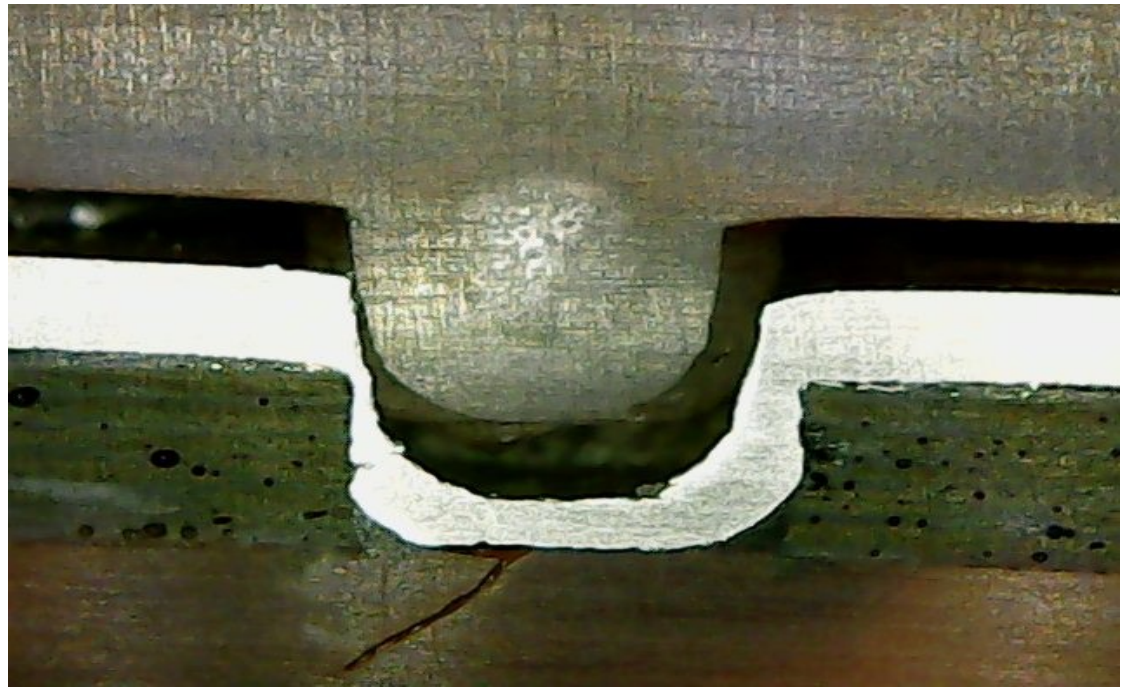

Gambar 16. Hasil foto makro spesimen metode clinching dengan diameter $4.5 \mathrm{~mm}$

Dari hasil proses pengujian pada spesimen foto makro maka didapatkan hasil berupa diameter rivet. Nilai diameter rivet yang diperoleh pada pengujian foto makro ini adalah sebagai nilai input yang diperlukan dalam menghitung luas penampang (Area), dimana rumus luas penampang adalah $A=\pi r^{2}$. Hasil pengujian foto makro pada spesimen riveting dengan diameter hole $3.5 \mathrm{~mm}$ didapatkan diameter rivet sebesar $2.95 \mathrm{~mm}$, maka luas penampangnya sebesar $6.83 \mathrm{~mm}^{2}$. Hasil pengujian foto makro pada spesimen clinching diameter hole $3.5 \mathrm{~mm}$, $4.0 \mathrm{~mm}, 4.5 \mathrm{~mm}$ didapatkan diameter rivet sebesar mm, maka luas penampangnya sebesar $\mathrm{mm}^{2}$. Dari hasil pengujian foto makro juga didapatkan nilai damage length (Celah) pada setiap batas sambungan antara rivet dengan material uji. Hal ini menyebabkan terjadinya peningkatan nilai maksimum load yang diterima oleh masing-masing spesimen single lap joint. Damage length tersebut akan menahan rivet agar tidak langsung patah Ketika menerima beban geser. Hasil pengujian foto makro pada spesimen riveting dengan diameter hole $3.5 \mathrm{~mm}$ tidak terdapat damage length, sehingga Ketika rivet menerima beban geser maka rivet langsung mengalami patah pada rivet yang dikarenakan beban yang diberikan melebihi beban yang yang diijinkan oleh rivet. Pada spesimen clinching dengan diameter hole $3.5 \mathrm{~mm}, 4.0 \mathrm{~mm}, 4.5 \mathrm{~mm}$ memiliki nilai maksimum load sebesar 1884 Newton. Hasil pengujian foto makro pada spesimen clinching terdapat damage length sebesar $0.01 \mathrm{~mm}$ pada sisi sambungnya dan memiliki nilai maksimum load sebesar 1884 Newton.

\section{Kesimpulan}

Dari hasil pengujian spesimen riveting didapatkan hasil rata-rata pada maksimum load yaitu sebesar 1059 Newton, rata-rata pada yield strength yaitu sebesar $113 \mathrm{~N} / \mathrm{mm}^{2}$ dan ratarata tensile strength yaitu sebesar $151 \mathrm{~N} / \mathrm{mm}^{2}$.Dari hasil pengujian spesimen clinching didapatkan hasil rata-rata pada maksimum load yaitu sebesar 1884 Newton, rata-rata pada yield strength yaitu sebesar $233 \mathrm{~N} / \mathrm{mm}^{2}$ dan rata-rata tensile strength yaitu sebesar 344 $\mathrm{N} / \mathrm{mm}^{2}$.Dari hasil penelitian ini didapatkan peningkatan maksimum load pada spesimen yang diuji dengan clinching karena pada spesimen tersebut didapatkan nilai damage length (Celah) pada batas sambungan antara rivet dengan material uji. Hal ini menyebabkan terjadinya peningkatan nilai maksimum load yang diterima oleh masing-masing spesimen single lap joint. Damage length tersebut akan menahan rivet agar tidak langsung patah Ketika menerima beban geser. Hal ini juga dapat dibuktikan dengan pengamatan yang dilakukan menggunakan alat mikroskop metalografi dan menggunakan perbesaran hingga 40 kali ukuran aslinya. 


\section{DAFTAR PUSTAKA}

[1] R. K. J.K. Gupta, A Textbook of Machine Design, India : S Chand \& Co Ltd; 14th edition, 2005.

[2] P. Tan, "Rivet Part Number," 13 july 2017. [Online]. Available: ourakuntansi2.blogspot.com. [Accessed 7 agustus 2020].

[3] M. A. Huda, Pengukuran mata pisau (Cutting EDGE) pahat pada proses drilling baja karbon AISI 1045 dengan metode Embedded Thermocouple, 2008.

[4] S. "Laporan Material Teknik Uji Tarik," 20 Juli 2011. [Online]. Available: serasihLaporan material teknik uji tarik. [Accessed 9 Agustus 2020].

[5] S. M. M., Composite Materials Handbook, New York: McGraw-Hill Book Company, 1984.

[6] A. S. H, Introduction to Physical Metallurgy, Second Edition, Tokyo: McGraw-Hill International Book Company, 1982.

[7] ASM Handbook Volume 9: Metallography and Microstructures, ASM International, 2004.

[8] [Online]. Available: http://repository.unpas.ac.id. [Accessed 20 Februari 2021].

[9] D. Surya, "Pengaruh pengaruh diameter hole terhadap kekuatan single lap joint pada material Aluminium 2024-T3 dalam kegiatan aircraft maintenance," 2018. 